\title{
Ancient DNA reveals genetic connections between early Di-Qiang and Han Chinese
}

\author{
Jiawei Li ${ }^{1}$, Wen Zeng ${ }^{2}$, Ye Zhang ${ }^{1}$, Albert Min-Shan $\mathrm{Ko}^{3}$, Chunxiang $\mathrm{Li}^{1}$, Hong Zhu ${ }^{2}$, Qiaomei $\mathrm{Fu}^{3 *}$ \\ and Hui Zhou ${ }^{1,2^{*}}$ (D)
}

\begin{abstract}
Background: Ancient Di-Qiang people once resided in the Ganqing region of China, adjacent to the Central Plain area from where Han Chinese originated. While gene flow between the Di-Qiang and Han Chinese has been proposed, there is no evidence to support this view. Here we analyzed the human remains from an early Di-Qiang site (Mogou site dated $\sim 4000$ years old) and compared them to other ancient DNA across China, including an early Han-related site (Hengbei site dated $\sim 3000$ years old) to establish the underlying genetic relationship between the Di-Qiang and ancestors of Han Chinese.

Results: We found Mogou mtDNA haplogroups were highly diverse, comprising 14 haplogroups: $A, B, C, D\left(D^{*}\right.$, D4, D5), F, G, M7, M8, M10, M13, M25, N*, N9a, and Z. In contrast, Mogou males were all Y-DNA haplogroup O3a2/P201; specifically one male was further assigned to $\mathrm{O} 3 \mathrm{a} 2 \mathrm{cla} / \mathrm{M} 117$ using targeted unique regions on the non-recombining region of the Y-chromosome. We compared Mogou to 7 other ancient and 38 modern Chinese groups, in a total of 1793 individuals, and found that Mogou shared close genetic distances with Taojiazhai (a more recent Di-Qiang population), Hengbei, and Northern Han. We modeled their interactions using Approximate Bayesian Computation, and support was given to a potential admixture of $~ 13-18 \%$ between the Mogou and Northern Han around 3300-3800 years ago.
\end{abstract}

Conclusions: Mogou harbors the earliest genetically identifiable Di-Qiang, ancestral to the Taojiazhai, and up to 33\% paternal and $\sim 70 \%$ of its maternal haplogroups could be found in present-day Northern Han Chinese.

Keywords: Di-Qiang population, Ancient DNA, Mitochondrial DNA, Non-recombining region of the Y-chromosome, Han Chinese population

\section{Background}

The Huaxia is the earliest Chinese dynasty to emerge $\sim 2000$ BC along the Yellow River. This population grew from the Central Plain area and later became established as the Han Chinese during the Han Dynasty (206 BC to 220 AD). Throughout history, the Han Chinese continued to have complex interactions with surrounding ethnic minority groups in their vicinity $[1,2]$, whose details are being studied and debated by historians, archaeologists, anthropologists and geneticists.

One important pastoral agriculturist group that interacted with the Han Chinese from the west near the upper reaches

\footnotetext{
*Correspondence: fuqiaomei@ivpp.ac.cn; zhouhui@jlu.edu.cn

${ }^{3}$ Key Laboratory of Vertebrate Evolution and Human Origins of Chinese

Academy of Sciences, IVPP, CAS, Beijing 100044, People's Republic of China

${ }^{1}$ College of Life Science, Jilin University, Changchun 130023, People's

Republic of China

Full list of author information is available at the end of the article
}

of the Yellow River in the Gansu-Qinghai (or Ganqing) region is a historical group called the Di-Qiang. Around the middle Neolithic, as people (including ancestors of the Han) expanded away from the Central Plain due to improved agricultural practices [3], they encountered the Di-Qiang people, and both groups have occupied the Ganqing $[4,5]$. A recent ancient DNA study goes further to suggest that a once Ganqing population, the Taojiazhai people, is related to the Di-Qiang, and even contributed genetically to the Han Chinese [6]. However, an issue with the Taojiazhai was that the archeological site dated to $\sim 1700-1900$ yr. BP, which occurred well within the time period of the Han dynasty, raising the possibility that some Taojiazhai individuals might have been admixed in Han Chinese.

In this study, we overcome this problem by investigation of the Mogou cemetery (Fig. 1), a considerably older Di-Qiang site in the Ganqing region that is enclosed by the Qinghai-Tibetan Plateau to the west and the Tengger 


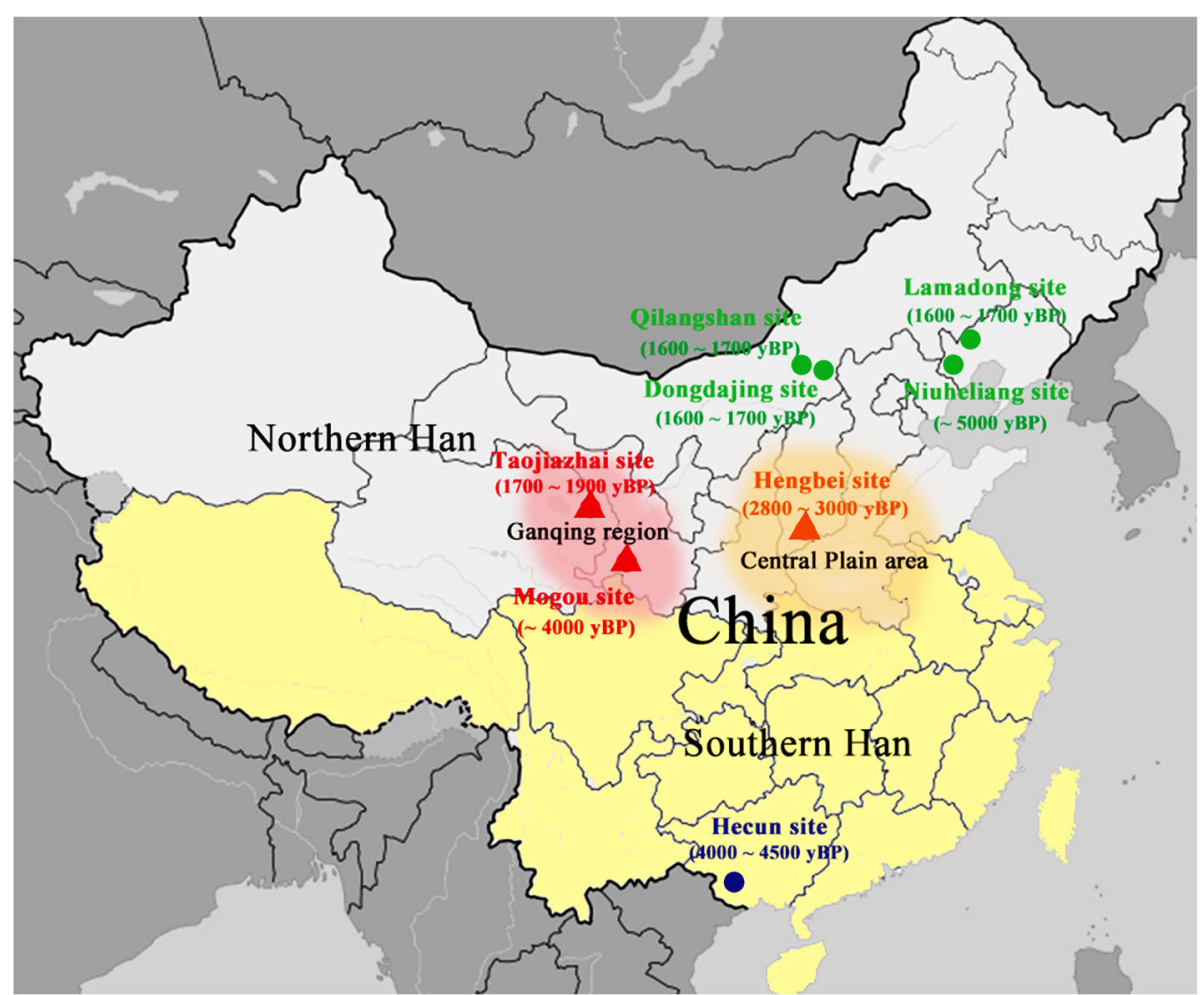

Fig. 1 Geographic location and estimated age of ancient groups used in this study. Ganqing region (shaded red) overlies the middle and upper reaches of the Yellow River and is adjacent to the Central Plain area (shaded orange), where ancestors of the Han lived

Desert to the north [7]. The accelerator mass spectrometry (AMS) radiocarbon dating of the Tomb M633 human bone samples (slightly more recent than specimens collected for this study) yielded $3145 \pm 45{ }^{14} \mathrm{C}$ yr. BP and 3526-3336 cal. yr. BP after correction with Damon's table [8]. Cultural artifacts, such as funerary pottery constructed of red clay with features found prominently in the Qijia culture, place this site in the late Neolithic to early Bronze Age ( 3600 to 4200 yr. BP) [9] and associated with the Di-Qiang [10]. So the Mogou represents an early Di-Qiang predating the Han dynasty.

To clarify the genetic relationship between the ancient Di-Qiang and early Han Chinese, we analyzed the new Di-Qiang from Mogou, using hyper variable sequence I (HVS-I) and coding region of mtDNA and nonrecombining region of Y-chromosome (NRY), and compared them to other ancient DNA and contemporary groups across China.

\section{Methods}

\section{Population samples and Mogou specimens}

A total of 1793 individuals were collected, belonging to 8 ancient (235 individuals) and 38 modern (1558 individuals) groups (Table 1). The Mogou site $\left(34^{\circ} 69^{\prime} \mathrm{N}\right.$ $103^{\circ} 86^{\circ} \mathrm{E}$ ) is located in the Tibetan Autonomous Prefecture of Gannan, Gansu Province, being at the geographical center of China and upstream of the Yellow river [7]. The high altitude (2209 to $3926 \mathrm{~m}$ ) and a continental climate with an annual average temperature of $3.28{ }^{\circ} \mathrm{C}$ are favorable to ancient DNA preservation [11]. The Institute of Cultural and Historical Relics and Archaeology in Gansu Province excavated the cemetery, consisting of 26 graves, with permission from the State Administration of Cultural Heritage who has control over the archaeological excavations in China. Nearly every grave contained multiple individuals due to the complex structure of the tomb. In total, 60 ancient human remains were exhumed from the Mogou site for genetic analysis (see Additional file 1).

\section{DNA extraction and laboratory environment}

Prior to DNA extraction, the samples were cleaned using a series of treatments to remove the exogenous contaminants on the surface of the samples [12]. All of the operations were performed in separate rooms of an ancient DNA laboratory to strictly avoid any external contamination. Procedures were carried out independently of molecular biology experiments using present day DNA.

Before powdering, the bones and teeth surfaces were wiped down using cotton soaked in sodium hypochlorite solution. Bones and teeth were then soaked in a 5\% sodium hypochlorite solution for $15 \mathrm{~min}$, and carefully rinsed with 95\% alcohol, and then UV-irradiated 
Table 1 List of populations used in this study

\begin{tabular}{|c|c|c|c|c|}
\hline $\begin{array}{l}\text { Ancient DNA } \\
\text { population }\end{array}$ & $n$ & $\begin{array}{l}\text { Approx. age } \\
\text { (yr BP) }\end{array}$ & Sampled location & References \\
\hline Mogou & 55 & 4000 & Gansu & This study \\
\hline Hecun & 9 & 4500 & Guangxi & Unpublished \\
\hline Lamadong & 17 & 1700 & Liaoning & [38] \\
\hline Hengbei & 64 & 3000 & Shanxi & [40] \\
\hline Niuheliang & 28 & 5000 & Liaoning & [41] \\
\hline Taojiazhai & 29 & 1900 & Qinghai & [6] \\
\hline Dongdajing & 17 & 1700 & Inner Monglia & [39] \\
\hline Qilangshan & 16 & 1700 & Inner Monglia & [37] \\
\hline $\begin{array}{l}\text { Modern } \\
\text { population }\end{array}$ & $n$ & Groups & Sampled location/ethnicity ( $n$ ) & \\
\hline Northern Han & 267 & 5 & Gansu (45), Qinghai (51), Shaanxi (53), Liaoning (51), Jiangsu (67) & $\begin{array}{l}{[16,17,42,} \\
43]\end{array}$ \\
\hline $\begin{array}{l}\text { Northern } \\
\text { minorities }\end{array}$ & 192 & 4 & Ewenki (47), Korean (48), Mongolian (49), Uygur (48) & {$[44,46]$} \\
\hline Southern Han & 168 & 5 & Fujian (54), Guangdong (29), Guangxi (26), Hunan (16), Yunnan (43) & $\begin{array}{l}{[16,17,42,} \\
43]\end{array}$ \\
\hline Miao-Yao & 215 & 4 & Hunan (102), Guangxi (73), Yunnan (40) & [48] \\
\hline Tai-Kadai & 397 & 11 & $\begin{array}{l}\text { Buyang (31), Caolan (30), Jiamao (27), Lingan (31), Mak (33), Mollao (29), Mulam (39), Pou (34), } \\
\text { Sui (30), Then (30), Zhuang (83) }\end{array}$ & {$[46,49]$} \\
\hline Austro-Asiatic & 84 & 3 & Bugan (32), Palyu (30), Va (22) & [49] \\
\hline Tibeto-Burman & 235 & 6 & Bai (90), Hani (33), Nakchu (30), Tibetan (35), Tujia (31), Yi (16) & [45-47] \\
\hline
\end{tabular}

overnight. For dried bone material, a drilling machine was used to remove the top layer to avoid any remaining surface contaminants, and then powder was obtained for DNA extraction by drilling holes into the remainder of the bone. For the teeth, the dental calculus on the surfaces of the teeth was removed before drilling dental cervix to obtain cavitas pulpae powder. A turbid solution was then created, containing a mixture of about $200 \mathrm{mg}$ of bone or tooth powder and $4.5 \mathrm{~mL} 0.5 \mathrm{mM}$ EDTA ( $\mathrm{pH} 8.0)$. This solution was stored at $4{ }^{\circ} \mathrm{C}$ for $24 \mathrm{~h}$, upon which $80 \mu \mathrm{L}$ of $100 \mathrm{mg} /$ $\mathrm{mL}$ of proteinase $\mathrm{K}$ was added. The resulting solution was placed in the hybridization oven overnight at $56{ }^{\circ} \mathrm{C}$. The precipitate was removed by centrifugation $(3 \mathrm{~min}$ at $8000 \mathrm{rpm}$ ), and the clear supernatant extract was concentrated to $100 \mu \mathrm{L}$ using an ultrafiltration tube (Centurion ${ }^{\odot}$ $\mathrm{YM}-10)$ at $8000 \mathrm{rpm}$ centrifugation. DNA was extracted using the concentrated solution in accordance with the QIAamp ${ }^{\oplus}$ Purification Kit manual. Furthermore, DNA extraction was performed at least twice for each sample, and every five ancient samples had one blank control.

\section{Measures taken to ensure authenticity}

To ensure the results are valid and reliable, we have kept in strict compliance with the rules indicated for extracting ancient DNA [13]. All laboratory personnel involved in the operation were female. Moreover, to obtain satisfactory results in ancient DNA research, the two guidelines were followed:

1) Pre-PCR and post-PCR protocols were carried out in two completely separate buildings. Experimenters were only allowed to move from the pre-PCR lab building to the post-PCR lab building each day, avoiding contamination from PCR products into the samples. The reverse was not allowed. The experimental areas including both the PCR room and the DNA extraction room have been equipped with Air Shower, which removes the dust, hair and other debris attached to clothes and reduces introduction of contaminants from laboratory personnel.

2) During the study period, we relocated our laboratory to a new campus, creating an opportunity to observe whether our results could be replicated in the new laboratory. Furthermore, different parts of the samples were randomly selected for replicate extraction and PCR amplification, in order to ensure the results are reproducible.

\section{Mitochondrial DNA amplification and haplogroup assignment}

Due to high degradation of DNA from the ancient samples, it is difficult to amplify long DNA fragments. We thus designed two sets of primers (see Additional file 2) 
to amplify and sequence the mtDNA HVS-I region between positions 16,051 and 16,384. We also used both the Sanger sequencing method and the amplified product-length polymorphisms (APLP) method [14, 15], through the design of two or three sets of specific and corresponding primers (see Additional file 2).

The PCR amplification was carried out in a $12.5 \mu \mathrm{L}$ reaction mixture containing $2 \mu \mathrm{L}$ of template DNA, $1.5 \times$ reaction buffer (Takara, Japan), $2.5 \mathrm{mM} \quad \mathrm{MgCl}_{2}$ (Promega, Germany), $0.25 \mathrm{mM}$ dNTPs (Takara, Japan), $0.1 \mu \mathrm{M}$ of each primer, $1 \mathrm{U}$ of ExTaq ${ }^{\circ}$ Hot Start Version DNA polymerase (Takara, Japan), $1 \mu \mathrm{L} 20 \mathrm{mg} / \mathrm{mL}$ BSA, and RNase-Free Water (Takara, Japan). Cycling parameters were described as follows: initial denaturation at $94{ }^{\circ} \mathrm{C}$ for $5 \mathrm{~min}$, followed by 34 cycles at $94{ }^{\circ} \mathrm{C}$ for $30 \mathrm{~s}$, 30 s at $55{ }^{\circ} \mathrm{C}$, elongation for 30 s at $72{ }^{\circ} \mathrm{C}$, with a final extension for $10 \mathrm{~min}$ at $72{ }^{\circ} \mathrm{C}$ and storage at $4{ }^{\circ} \mathrm{C}$. Then, the PCR amplification products were examined by agarose gel electrophoresis. After the purification with the QIA quick Gel Extraction Kit (Qiagen, Germany), the amplification products were sequenced using the BigDye ${ }^{\bullet}$ Terminator V3.1 Cycle Sequencing kit (Applied Biosystems, USA). These sequences were analyzed, and an output file was generated from the ABI PRISM ${ }^{\mathrm{sw}} 310$ automatic sequencer. In the end, the mtDNA haplogroups were called based on SNPs from the hypervariable and the coding regions, and the East Asian mtDNA classification tree [16, 17].

\section{Sex identification and Y-DNA haplogroup assignment}

The sex of the ancient specimens was determined by PCR analysis of the X-Y Amelogenin Gene (AMG-PCR) [18]. The primers are listed in Additional file 2. The Y Chromosome SNPs M9, M214, M175, M122, M324, and P201 were typed for the detection of the following haplogroups: K, NO, O, O3, O3a, and O3a2 [19-22]. The YDNA haplogroups were called according to SNPs listed in ISOGG 2014 (https://isogg.org/).

Non-recombining region of the $Y$ chromosome (NRY) capture We performed NRY capture of two Mogou males (MG18 and MG48). The DNA library was prepared with NEBNext $^{\circ}$ Ultra $^{\text {tx }}$ DNA Library Prep Kit for Illumina ${ }^{\circ}$ in accordance to manufacturer's instructions, which is similar to the Illumina TruSeq V2 protocol [23]. This library preparation will perform end repair with $5^{\prime}$ phosphorylation and $\mathrm{dA}$-tailing, and make the damage-derived $\mathrm{C}$ - to- $\mathrm{T}$ in the $5^{\prime}$-endoverhang fragments to have the reverse complement nucleotides G-to-A substitutions at the 3 '-end. After the ligation with NEBNext Adaptors (that includes hairpin loop with uracil), the uracils in the adaptor and DNA insert are then removed by USER (uracil-DNA-glycosylase (UDG) and endonuclease VIII), which would cause a small residual signal of C-to-T substitutions to be detected at the $5^{\prime}(\sim 1.8 \%)$ and no influence to the G-to-A substitutions at 3' terminal positions (for MG18 11\% and for MG48 16\%) [23]. However, within a CpG context, because the majority of cytosines are methylated invertebrate genomes, which when deaminated, leaves thymine instead of uracil, the deaminated cytosines in the majority of cases are not removed in this CpG part even with the USER treatment (CpG part: C-to-T substitutions for MG18 $\sim 11 \%$ and for MG48 15\%, see Additional file 3).

Next, the 7.18 Mb targeted unique regions on the NRY chromosome was used to design the array. We used a similar experimental method of the one described by $\mathrm{Fu}$ et al. [24], to do the in-solution hybridization enrichment for the libraries. We then focused on the reads passing Illumina quality control that had the expected index combinations for these libraries. We sequenced the libraries on the HiSeq X-Ten platform. We restricted analysis to pairs of reads that had at least 11 base pairs of overlap, merged the reads, and then mapped the merged sequences to the human genome reference hg19 using BWA. We removed duplicated molecules prior to analysis to reduce the influence of mapping errors. We restricted our analysis to unique regions in the genome, using Tandem Repeat Finder (for hg19) and mapability tracks (map 35-50\%). Details of sequencing coverage on NRY are shown in Table 2. The fragments size distribution of two Mogou male specimens show short length fragments, which are typical for ancient DNA (see Additional file 4).

\section{Genetic analysis}

Chromas 2.4.1 and Sequencher 5.2.3 were used for sequence assembly and to check sequence alignment. Genetic distances (based on Fst [25]) between populations are shown using Multidimensional Scaling (MDS), and Analysis of Molecular Variance (AMOVA) were calculated in Arlequin (v3.5.1.2) [26]. The mtDNA haplogroup frequencies were shown using Principal Component Analysis (PCA). Temporal networks or

Table 2 Sequencing metrics for two libraries of NRY capture

\begin{tabular}{|c|c|c|c|c|c|c|}
\hline Library & $\begin{array}{l}\text { Total fragments } \\
\text { (length } \geq 35 \mathrm{bp} \text { ) }\end{array}$ & $\begin{array}{l}\text { Aligned fragments (length } \geq \\
35 \text { bp \& map quality }>=30 \text { ) }\end{array}$ & $\begin{array}{l}\text { Fragments on target (length } \geq \\
35 \text { bp \& map quality }>=30 \text { ) }\end{array}$ & $\begin{array}{l}\text { Fragments on target after } \\
\text { duplicate removal (length } \geq 35 \mathrm{bp} \text { ) }\end{array}$ & $\begin{array}{l}\text { Average } \\
\text { duplicates }\end{array}$ & Coverage \\
\hline MG18 & $21,590,365$ & $4,455,311$ & $4,095,184$ & 44,977 & 91 & 0.59 \\
\hline MG48 & $23,458,692$ & $13,692,019$ & $10,262,330$ & 752,478 & 14 & 8.51 \\
\hline
\end{tabular}


TempNet [27], which shows networks stacked in three dimensions (3-D), was used to explore the continuity of haplotypes across time. The phylogeny of Y-DNA haplogroup $\mathrm{O}$ was inferred using Figtree in the BEAST program [28] and tip dating of ancient DNA [29]. Demographic histories were simulated using Fastsimcoal [30] and parameter distributions inferred by Approximate Bayesian Computation (ABC) [31].

\section{Results}

A total of 55 of 60 samples from the Mogou site (Additional file 1) were successfully replicated, and verified to be different from the mtDNA of laboratory personnel (see Additional file 5). All sequences were submitted to GenBank under the accession numbers KX085423-KX085477.

\section{Mitochondrial DNA analysis}

The organic preservation was relatively high for Mogou, most likely related to its high elevation and low temperature. For example, from the captured MG48 library, we obtained 97-fold coverage for the mtDNA genome. The contamination of MG48 was $0.048 \%$ (95\% C.I. $0.545 \%-0.008 \%$ ) based on the match rate to the mtDNA consensus by running the contamination estimator ContamMix [24]. We genotyped 55 samples for mtDNA HVS-I and nt1040 $0 \mathrm{~T} / \mathrm{C}$ (for the M/N type), and further SNP loci detection was carried out on the coding region to ensure that haplogroup was correctly called based on the results of the HVS-I motif. We found a total of 46 haplotypes (Table 3) with certain haplotypes shared by two or more individuals buried in the same grave, suggesting a matrilineal kinship among some individuals. The haplotypes were analyzed using the correction criterion developed by Alzualde et al. [32] to control for the reduction in the genetic diversity due to kinship [33]. Table 3 shows these haplotypes could be assigned to 14 mtDNA haplogroups: A, B, C, D (D*, D4, and D5), F, G, M7, M8, M10, M13, M25, N*, N9a, and Z. Additional file 6 shows the more frequent Mogou haplogroups were D (34.78\%), C (10.87\%), A (8.70\%), and F (8.70\%), while the M8, M13, M25, and $\mathrm{N}^{*}$ have only one individual each. Most of these haplogroups occur among East Asians [16] with M25 found in South Asians [34].

AMOVA was used to test how different classifications would affect the variance among groups (Additional file 7). We found geography explained the most variance among groups. Compared to the variance given when all groups were independent (variance among groups $=2.01 \%$ ), the highest variance (variance among groups $=1.64 \%$ ) was observed when two geographic groups were classified, i.e. Northern China (Mogou, Hengbei, Taojiazhai, Northern Han and Northern minorities, Tibeto-Burman) and Southern China (Southern Han and Southern minorities).
The Tibeto-Burman was better grouped with Northern China than independently (variance among groups = $1.33 \%$ ) or with Southern China (variance among groups = 1.29\%). The ancient groups (Mogou, Hengbei, Taojiazhai) associated more with Northern Han (variance among groups $=1.36 \%$ ) than with Northern minorities (variance among groups $=1.09 \%$ ).

\section{Y-chromosome analysis}

Of the 55 samples, 15 males and 17 females were identified using molecular biology techniques. Remaining 23 samples were indeterminate for sex after testing the AMG-PCR product. Only six amplified Y-SNP products could be successfully replicated. Table 4 shows all six Mogou males belonged to Y-DNA haplogroup O3a2/ P201. The two male specimens (MG18 and MG48) selected for capture $7.18 \mathrm{Mb}$ of the NRY chromosome, after retaining positions with coverage at least 3-fold, their Y-DNA haplogroups were identified to be O3a2c and O3a2c1a/M117, respectively. The MG48 was further analyzed since a higher 8.51 -fold coverage was better to build the consensus.

We aligned MG48 with the published 71 HGDP East Asian individuals with $\mathrm{O}$ haplogroup [35] to verify that it could be properly placed within the haplogroup $\mathrm{O}$ lineage. The consensus length, between MG48 (retaining positions with coverage of at least 3-fold) and HGDP Ychromosome dataset, was $381,473 \mathrm{bp}$. Figure 2 shows that all 72 sequences could be confidently assigned to Y-DNA haplogroup O1, O2, O3 using 31 ISOGG defining SNPs, and that the posteriors leading up to the O3a2c clade that the MG48 falls under were 1.0, thus ensuring that its position was highly resolved. The inferred Y-DNA substitution rate of $7.76 \times 10^{-10}\left(95 \%\right.$ CI $3.89 \times 10^{-10}$ to $\left.1.13 \times 10^{-9}\right)$ per site per year remained consistent with other ancient DNA studies [36].

\section{MDS of mtDNA genetic distances (Fst)}

We calculated the genetic distance Fst and permutated $P$-values of the ancient $[6,37-41]$ and modern groups [16, 17, 42-49] based on mtDNA sequences. Additional file 8 shows that genetic distances were not significant between Mogou and Hengbei (Fst $=0.003)$, Taojiazhai $($ Fst $=0.005)$, Northern Han $($ Fst $=0.0004)$, Northern minorities $($ Fst $=$ $0.005)$ then followed by Dongdajing ( $\mathrm{Fst}=0.01)$, Qilangshan $(\mathrm{Fst}=0.02)$, and Lamadong $(\mathrm{Fst}=0.02)$. However, there were significant genetic distances between Mogou and Hecun $(\mathrm{Fst}=0.08)$, Niuheliang $(\mathrm{Fst}=0.05)$, Southern Han $(\mathrm{Fst}=0.03)$, Miao-Yao (Fst $=0.03)$, Tai-Kadai $(\mathrm{Fst}=$ 0.05), Austro-Asiatic (Fst $=0.04$ ), and Tibeto-Burman (Fst $=0.01)$. Figure 3 shows MDS plot $($ MDS stress $=0.001)$ of a comparison among ancient samples, where Northern and Southern China divided in the first dimension, but Mogou, Hengbei and Taojiazhai clustered together. 
Table 3 mtDNA nucleotide changes in 55 Mogou samples

\begin{tabular}{|c|c|c|c|c|}
\hline Haplotype & Specimen & Haplogroup & Coding region SNPS & Mutations in mitochondrial HVS-I (160001+) \\
\hline ht1 & MG28 & A & $10,400,663$ & 086-223-290-319-362 \\
\hline ht2 & MG20 & A & $10,400,663$ & 093-129-223-284-290-319-362 \\
\hline ht3 & MG23 & A & $10,400,663$ & 051-129-182C-183C-189-290-319-362 \\
\hline ht4 & MG24 & A & $10,400,663$ & $223-290-311-319-362$ \\
\hline ht5 & MG8 & B & 9 bp deletion & $111-140-183 C-189-234-243$ \\
\hline ht6 & MG57 & & & \\
\hline ht7 & MG21 & C & $10,400,14,318$ & $223-298-327$ \\
\hline ht8 & MG37 & & & \\
\hline ht9 & MG36 & C & $10,400,14,318$ & $093-129-223-298-327$ \\
\hline ht10 & MG41 & C & $10,400,14,318$ & $093-129-188-223-298-327$ \\
\hline ht11 & MG50,MG51, MG54 & C & $10,400,14,318$ & $129-192-223-298-327$ \\
\hline ht12 & MG38 & $D^{*}$ & $10,400,5178$ & $129-223-362$ \\
\hline ht13 & MG33 & $D^{*}$ & $10,400,5178$ & $151-223-290-362$ \\
\hline ht14 & MG11 & D4 & $10,400,5178,3010$ & 223-362 \\
\hline ht15 & MG22 & & & \\
\hline ht16 & MG47, MG52, MG53 & & & \\
\hline ht17 & MG3, MG5, MG6 & D4 & $10,400,5178,3010$ & $223-274-362$ \\
\hline ht18 & MG45 & & & \\
\hline ht19 & MG48 & D4 & $10,400,5178,3010$ & $129-223-274-362$ \\
\hline ht20 & MG4 & D4 & $10,400,5178,3010$ & 223-311-362 \\
\hline ht21 & MG40 & D4 & $10,400,5178,3010$ & 223-343-362 \\
\hline ht22 & MG19 & D4 & $10,400,5178,3010$ & $223-292-311-328-362$ \\
\hline$h+23$ & MG10 & D5 & $10,400,5178,10,397$ & $126-182 C-183 C-189-223-362$ \\
\hline ht24 & MG55 & D5 & $10,400,5178,10,397$ & 129-164-172-182C-183C-189-223-266-362 \\
\hline ht25 & MG58 & & & \\
\hline$h+26$ & MG18 & D5 & $10,400,5178,10,397$ & 092-164-172-182C-183C-189-223-266-362 \\
\hline $\mathrm{ht} 27$ & MG32 & & & \\
\hline ht28 & MG35 & $\mathrm{F}$ & 3970 & 189-304 \\
\hline ht29 & MG42 & & & \\
\hline ht30 & MG44 & $\mathrm{F}$ & 3970 & 183C-189-304 \\
\hline ht31 & MG31 & $\mathrm{F}$ & 3970 & 183C-189-232A-249-304 \\
\hline ht32 & MG59 & G & $10,400,4833$ & $129-223-261-278-311-362$ \\
\hline ht33 & MG43 & G & $10,400,4833$ & $086-153-223-278-362$ \\
\hline ht34 & MG25 & M7 & $10,400,6455$ & $223-295-362$ \\
\hline ht35 & MG27 & M7 & $10,400,6455$ & $223-294-295-362$ \\
\hline ht36 & MG14 & M8 & $10,400,15,487 \mathrm{~T}$ & 184-223-298-319 \\
\hline ht37 & MG9 & M10 & $10,400,10,646$ & $223-311$ \\
\hline ht38 & MG29, MG30 & & & \\
\hline ht39 & MG49 & M10 & $10,400,10,646$ & 093-129-193-223-311-357 \\
\hline ht40 & MG39 & M13 & $10,400,6023$ & 145-188-189-192-223-311-381 \\
\hline ht41 & MG60 & M25 & & $223-304$ \\
\hline ht42 & MG2 & $N^{*}$ & 10,398 & $223-243-256$ \\
\hline ht43 & MG7 & N9a & 5417 & $114-223-261$ \\
\hline ht44 & MG13 & N9a & 5417 & $223-257 \mathrm{~A}$ \\
\hline
\end{tabular}


Table 3 mtDNA nucleotide changes in 55 Mogou samples (Continued)

\begin{tabular}{lllll}
\hline Haplotype & Specimen & Haplogroup & Coding region SNPs & Mutations in mitochondrial HVS-I (160001+) \\
\hline ht45 & MG15, MG16, MG17 & $Z$ & $10,400,15,784$ & $185-223-260-298$ \\
ht46 & MG12 & $Z$ & $10,400,15,784$ & $185-223-259-260-298$
\end{tabular}

Figure 4 shows MDS plot (stress $=0.09$ ) of a comparison between ancient and modern populations, where Mogou associated with the Northern minority and Southern minority (e.g. Austro-Asiatic) in the first dimension, and with the Hengbei and Northern Han (e.g. Shaanxi, Qinghai, Gansu) in second dimension. Hengbei and Taojiazhai both associated with the Northern Han (e.g. Han Shaanxi, Qinghai), and differed from Mogou in their increased associations with Southern minorities.

\section{PCA of mtDNA haplogroup frequencies}

Figure 5 shows Mogou is located at the center of PCA among the Chinese and Tibetans. Entering from bottom right are the Northern Han [16, 17, 42, 43] and Northern minorities $[44,46]$. From the top left are Southern minorities $[46,48,49]$ then the Southern Han [16, 17, 42, 43]. The Tibeto-Burman speakers [45-47] enters from the top right of this cluster (for details on mtDNA haplogroup frequencies, see Additional file 9).

\section{Temporal network analysis}

To identify whether Di-Qiang did have an influence on Han Chinese, we investigated the temporal network of Mogou, Taojiazhai, and Northern Han. Figure 6a shows haplotypes between Mogou and Taojiazhai were contiguous, and some sharing with Northern Han. Figure $6 \mathrm{~b}$ shows that Mogou and Hengbei shared relatively more haplotypes with Northern Han compared to Taojiazhai.

\section{Approximate Bayesian computation (ABC) simulations}

To understand the genetic relationship between Mogou, Hengbei, and Northern Han, we proposed four models (Model 1-4; Fig. 7) that described the possible demographic history that occurred among them. After performing 1 million simulations for each model, the probability of model occurrence was assessed by two methods: acceptance-rejection (AR) [50] and weightedmultinomial logistic regression (LR) [31]. The quality of simulations was evaluated by $\mathrm{R}^{2}$, coverage, etc. compared to 1000 pseudo-observed, as described elsewhere [51]. The best supported model was Model 1 (49-79\%) followed by Model 3 (16-31\%; Fig. 7). We found the reason for the similarity between Model 1 and 3 was because Model 1 described Mogou contributed relatively few genes averaging at 15\% (95\% CI: 13-18\%) into Northern Han around 3500 years ago (95\% CI: 33013809; details in Table 5), which could approximate Model 3 that explained Northern Han is closer to Hengbei. The overall simulation quality was good, with the type I error (misclassified true models based on 1000 resamplings) of the four models being low $\sim 18 \%$. Every parameter were estimated with high coverage and $R^{2}>$ $10 \%$ indicating that they were reliably estimated [51], and there were noticeable improvements (on average $\sim 12$-fold; Additional file 10) to the posteriors of summary statistics used.

\section{Discussion}

In this study, we found that Mogou, being situated at the geographic center of China, also lay at intersection of Northern and Southern Chinese and Tibetans in terms of haplogroup frequencies, suggesting it plays an important role in the formation of early cultures along the Yellow River. We argue that it possibly has a northern origin, since more than $90 \%$ of its maternal haplogroups (A, B, C, D, F, G, M7, M8, M10, N9a, and Z) matches with those typically found among ancient groups across Northern China. In particular, the most frequent haplogroup D in Mogou (34.78\%) is consistent with other ancient northern groups (Qilangshan 43.75\%;

Table 4 Y-DNA haplogroup-defining SNPs of Mogou males

\begin{tabular}{|c|c|c|c|c|c|c|c|c|c|c|}
\hline \multirow[t]{3}{*}{ Specimen } & $C$ & $\mathrm{~F}$ & K & NO & $\mathrm{N}$ & O & $\mathrm{O} 3$ & O3a & O3a2 & \multirow[t]{3}{*}{ Haplogroup } \\
\hline & M216 & M89 & M9 & M214 & M231 & M175 & M122 & M324 & P201 & \\
\hline & $C \rightarrow T$ & $\mathrm{C} \rightarrow \mathrm{T}$ & $C \rightarrow G$ & $\mathrm{~T} \rightarrow \mathrm{C}$ & $\mathrm{G} \rightarrow \mathrm{A}$ & $-5 b p$ & $T \rightarrow C$ & $C \rightarrow G$ & $\mathrm{~T} \rightarrow \mathrm{C}$ & \\
\hline MG3 & $C$ & $T$ & $G$ & $C$ & $G$ & $-5 b p$ & $C$ & $G$ & $C$ & O3a2 \\
\hline MG9 & $C$ & T & G & $C$ & G & $-5 b p$ & C & G & $C$ & O3a2 \\
\hline MG18 & $C$ & T & G & $C$ & G & $-5 b p$ & C & G & $C$ & 03a2 \\
\hline MG44 & $C$ & $\mathrm{~T}$ & G & $C$ & G & $-5 b p$ & C & G & $C$ & O3a2 \\
\hline MG48 & $C$ & T & G & $C$ & G & $-5 b p$ & C & G & $C$ & O3a2 \\
\hline MG53 & $C$ & $\mathrm{~T}$ & G & $C$ & G & $-5 b p$ & C & G & $C$ & 03a2 \\
\hline
\end{tabular}




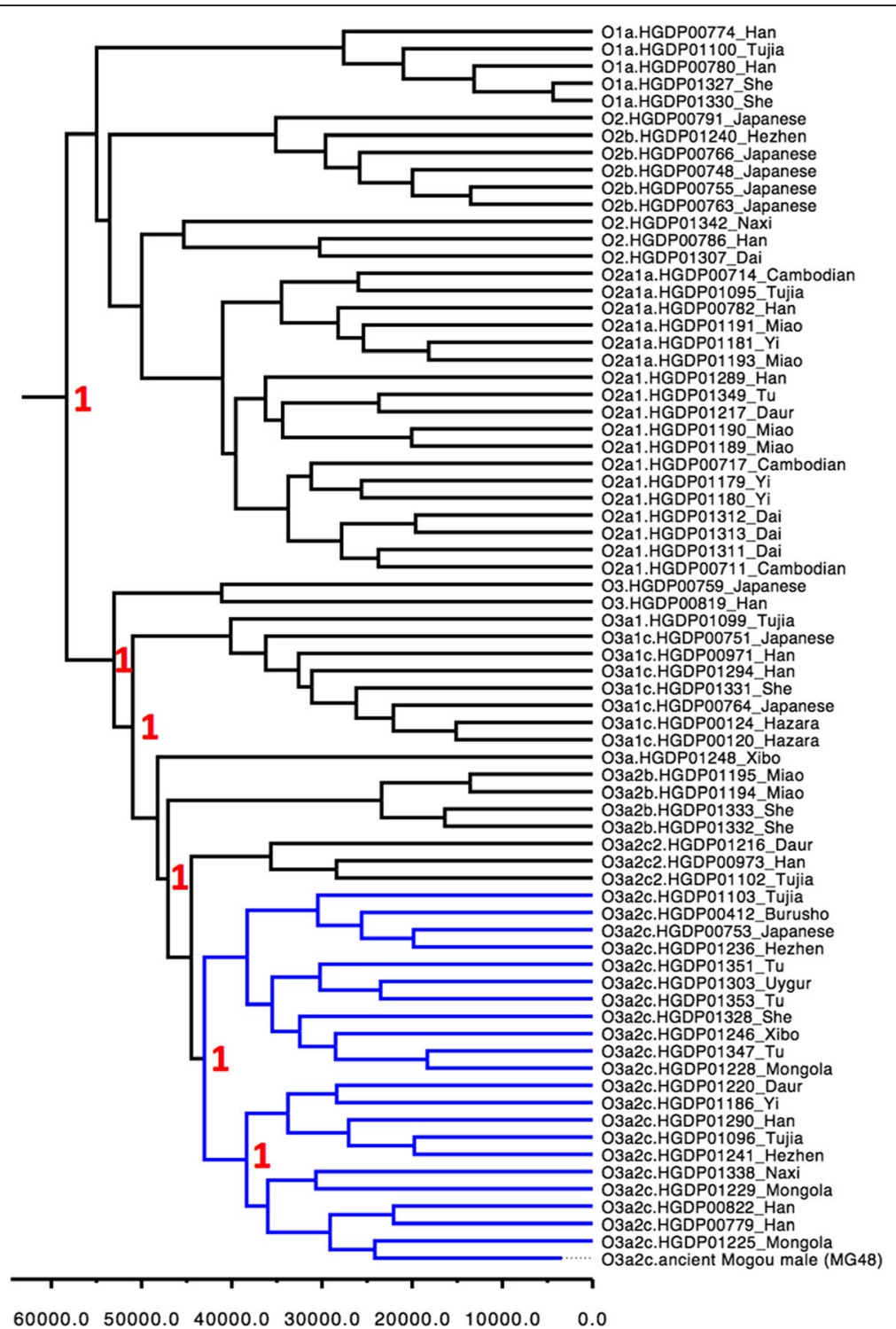

Fig. 2 Mogou male (MG48) was grouped under O3a2c on Y-DNA haplogroup O lineage using BEAST. O3a2c branches (blue); X-axis denotes time in yr. BP, and posterior values shown in red

Dondajing 41.17\%; Niuheliang 28.57\%; Taojiazhai 27.59\%; Hengbei 23.44\%; Lamadong 17.6\%) and less frequent in ancient southern group (Hecun 9.09\%, unpublished). Genetic distance also shows that Mogou is closely related to two northern ancient groups (Hengbei and Taojiazhai). AMOVA further supports the grouping of these ancient DNAs alongside Tibetans and Northern Han and Northern minorities in explaining the highest variance among groups $(1.64 \% ; P$-value $<0.01)$.

The closest ancient relative to Mogou in our dataset was the Hengbei people (genetic distance Fst $=0.003$ ), a $\sim 3000$ yr. BP population from the Central Plain region. Mogou and Hengbei shared about 33\% Y-DNA haplogroup O3a/M324, as well as several maternal haplogroups (D, A,
F, M10) and haplotypes (No. ht7, ht8, ht14, ht15, ht16, ht37, ht38, ht45). Because the temporal network showed a continuity of haplotypes across Mogou, Hengbei, and Northern Han, we investigated this further by constructing 4 model scenarios on how their relationship might have occurred. A higher model probability was assigned to a history where the Northern Han received 13-18\% maternal genes from Mogou around 3300-3800 years ago (Table 5) predating the formation of the Han.

The second closest ancient relative to Mogou was the Taojiazhai (genetic distance Fst $=0.005$ ). All Mogou and Taojiazhai males shared 100\% Y-DNA haplogroup O3a/ M324, and many maternal haplogroups (D4, M10, F, Z) and haplotypes (No.ht14, ht15, ht16, ht28, ht29, ht37, 


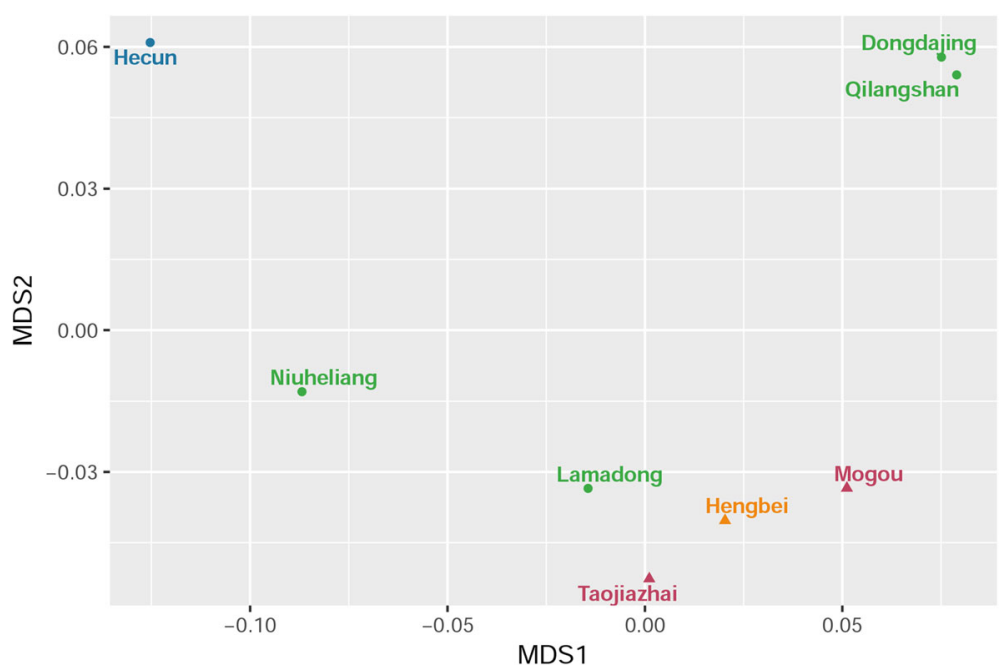

Fig. 3 MDS plot of genetic distance Fst between 8 ancient groups

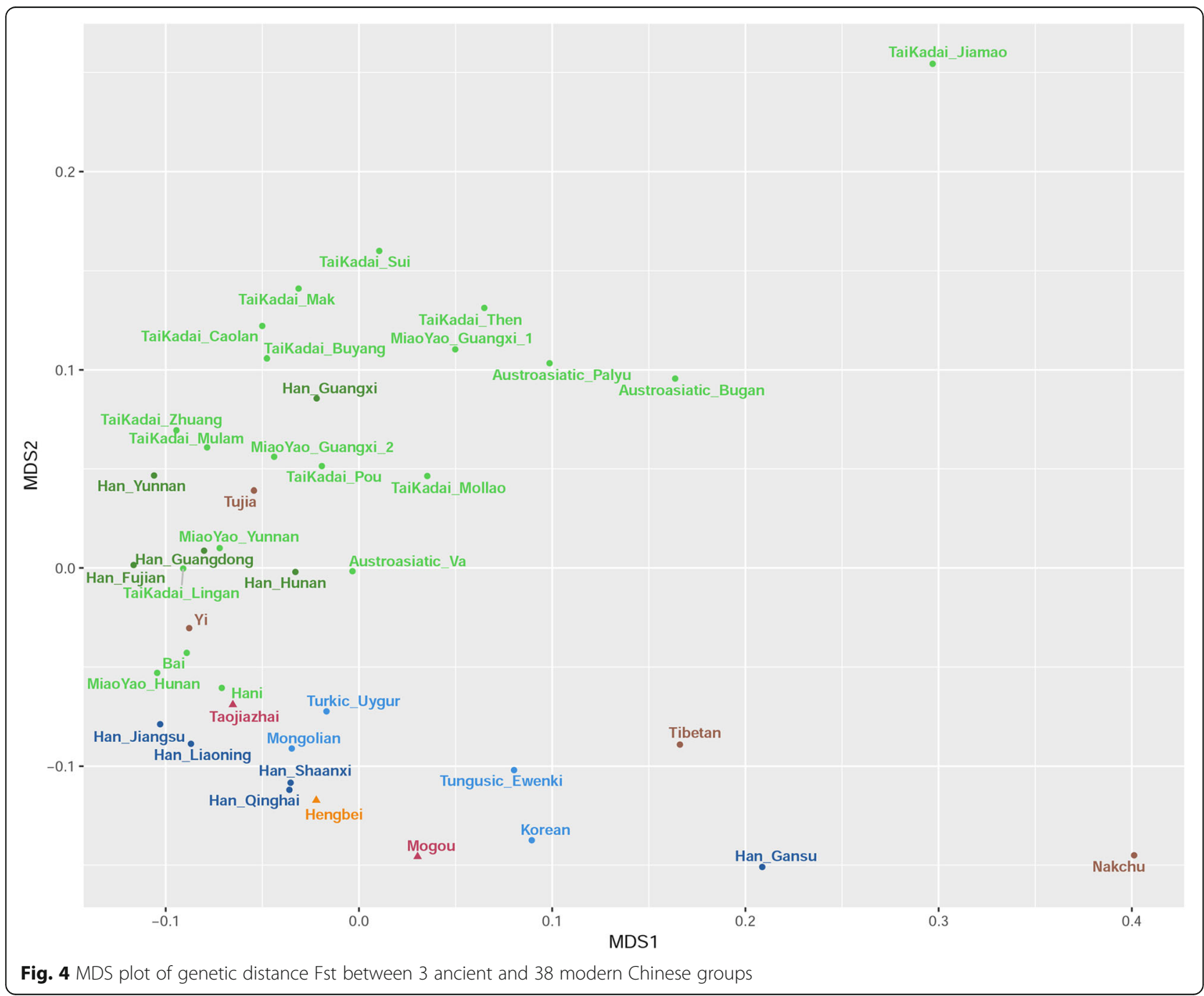



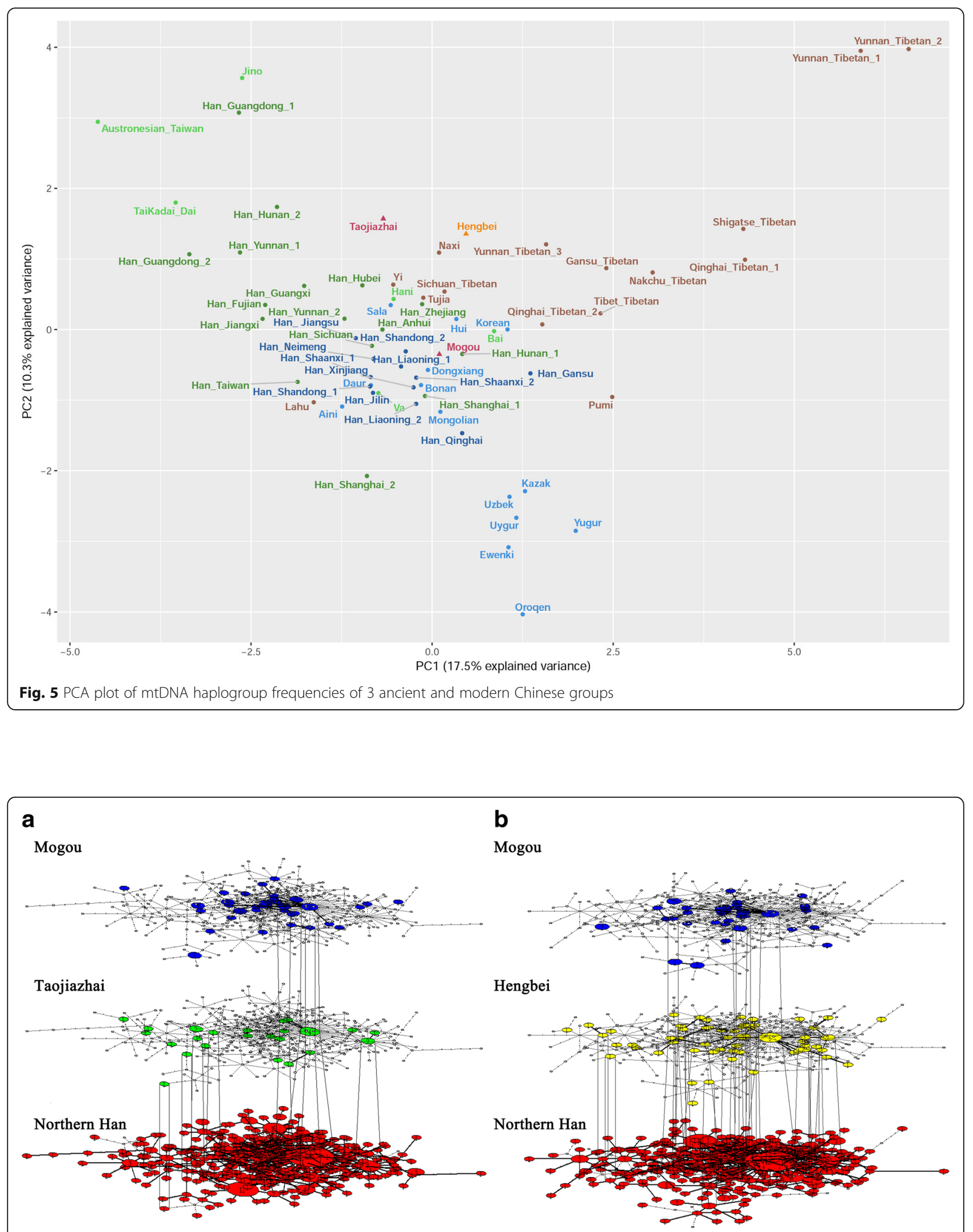

Fig. 6 Temporal network of haplotype distribution across time. a Haplotype sharing across 46 Mogou individuals, 29 Taojiazhai individuals, and 521 Northern Han; b Haplotype sharing across 46 Mogou individuals, 64 Hengbei individuals, and 521 Northern Han 


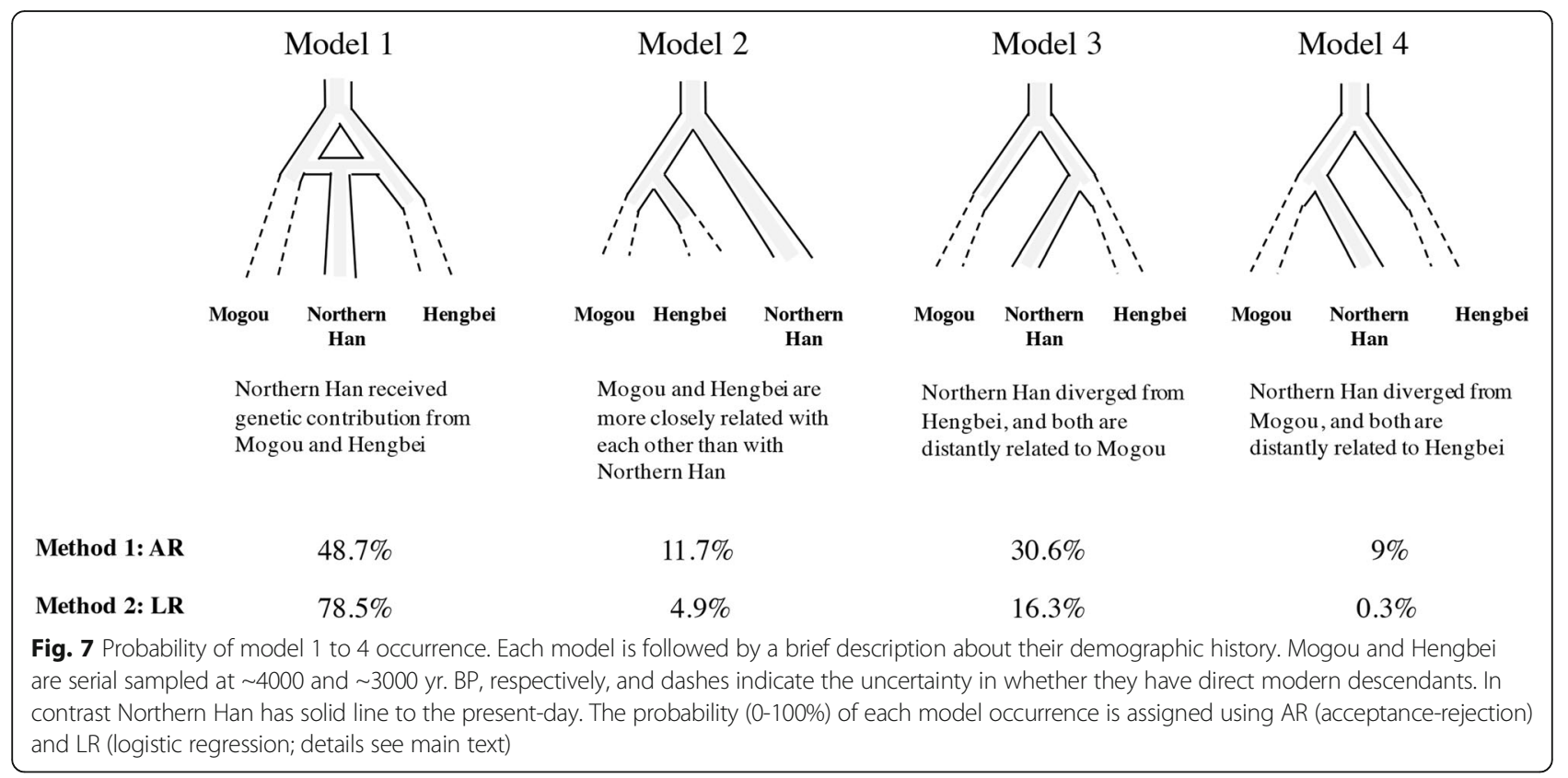

ht38, and ht45). Few haplotypes were carried across to the Northern Han on the temporal network. However, the Taojiazhai appeared to differ from the Mogou in its increased association with the modern Southern Chinese in terms of haplogroup frequencies and Fst genetic distance.

The closest modern relative to Mogou was the Northern Han (genetic distance Fst $=0.002$ ) and the Northern minorities (Fst $=0.005)$, and then more distantly by the Southern Han $($ Fst $=0.03)$ and Southern minorities (Fst = 0.03-0.05). Generally, the Y-DNA haplogroup O3a2/P201 from Mogou males is a common subtype of the O3a/ M324 branch, which occurs at a high frequency in extant Han Chinese (43.37\%) [43]. One Mogou male (MG48) was further identified as O3a2c1a/M117, which is a subclade of O3a2c1-M134 that is commonly found in SinoTibetan speakers and neighboring countries (e.g. Nepal, Bhutan, and Korea), but varies greatly in frequency among
Miaoyao speakers. Furthermore, MG48 clustered with Han and Tibeto-Burman (e.g. Naxi, Yi, and Tujia) as opposed to southern groups (e.g. Dai, Miao) on the HGDP Y-DNA haplogroup O lineage (Fig. 2).

Finally, the present-day Tibeto-Burman speakers were also close to Mogou (genetic distance Fst $=0.01$ ) than the Southern Han or Southern minorities. This was in agreement with historical records about the migration of ancient Di-Qiang people in the past. Some spread eastward, scattering in the middle reaches of the Yellow River, while others migrated southwest to form the Tubo, who are the ancestors of modern Tibetans, as well as contributing to the Southwestern minorities through integrating with the local population $[5,10]$.

\section{Conclusion}

We identified Mogou to be the earliest $\sim 4000 \mathrm{yr}$. BP Di-Qiang population, and genetically related to

Table 5 Parameter estimates of best supported Model 1

\begin{tabular}{|c|c|c|c|c|c|c|c|c|c|c|c|c|c|}
\hline \multirow[t]{2}{*}{ Population } & \multirow[t]{2}{*}{ Prior } & & & \multirow[t]{2}{*}{ Distribution } & \multirow[t]{2}{*}{ Mean } & \multirow[t]{2}{*}{ Mode } & \multicolumn{2}{|c|}{$95 \%$ HPD } & \multicolumn{5}{|c|}{ Pseudo-observed } \\
\hline & & & & & & & & & $\mathrm{R}^{2}$ & Bias & RMSE & Coverage & Factor 2 \\
\hline Mogou & 1 & - & 100,000 & Uniform & 799 & 824 & 699 & 887 & 0.45 & 0.18 & 0.33 & 85 & 0.94 \\
\hline Hengbei & 1 & - & 100,000 & Uniform & 1489 & 1559 & 1356 & 1759 & 0.84 & 0 & 0.11 & 90 & 1 \\
\hline Northern Han & 1 & - & 100,000 & Uniform & 657 & 600 & 596 & 826 & 0.9 & -0.1 & 0.26 & 90 & 1 \\
\hline T1 & 1 & - & 20,000 & Uniform & 5472 & 5661 & 5253 & 6389 & 0.76 & -0.02 & 0.16 & 70 & 1 \\
\hline $\mathrm{T} 2$ & 1 & - & 20,000 & Uniform & 3505 & 3703 & 3301 & 3809 & 0.51 & -0.02 & 0.15 & 80 & 1 \\
\hline $\mathrm{a}$ & 0.01 & - & 1 & Uniform & 0.146 & 0.143 & 0.127 & 0.183 & 0.44 & 0.94 & 1.12 & 79 & 0.7 \\
\hline
\end{tabular}

Mogou, Hengbei, Northern Han are effective haploids

T1, Divergence time between Mogou and Hengbei (yr BP)

$\mathrm{T} 2$, admixture time between Mogou and Hengbei (yr BP)

a, proportion of admixture from Mogou into Northern Han

$\mu$, mtDNA (control region) substitution rate $9.883 \times 10^{-8}$ per site per year were used according to ancient DNA-calibrated rates [52] 
Taojiazhai in sharing up to $100 \%$ paternal (O3a) and $\sim 60 \%$ maternal (D4, M10, F, Z) haplogroups. Among the alternative models considered, simulations demonstrated that Mogou and Hengbei once contributed genes into the early Northern Han. Thus, Mogou is also similar with the Northern Han in sharing up to 33\% paternal (O3a) and $~ 70 \%$ maternal (D, A, F, M10) haplogroups. We deduced that some Di-Qiang people had merged into the ancestral Han population. As societies developed, the communication and blending of different regions and cultures continued to be strengthened.

\section{Additional files}

Additional file 1: Sampling information of Mogou site. (XLSX $13 \mathrm{~kb}$ )

Additional file 2: Primers used in this study. (XLSX $11 \mathrm{~kb}$ )

Additional file 3: Damage pattern of two Mogou male specimens MG18 (a) and MG48 (b). Only sequences of at least 35 bp that aligned to the human genome with a map quality of at least 30 were considered for this figure. Substitution frequencies are shown both for $\mathrm{CpG}$ and non-CpG context. (PDF 806 kb)

Additional file 4: Fragment size distribution of two Mogou male specimens MG18 (a) and MG48 (b). Only 8\% of sequences merged from overlapping paired-end reads were considered for this figure. (PDF $178 \mathrm{~kb}$ )

Additional file 5: Variable sites of mitochondrial HVS-I sequences and $Y$ chromosome haplogroups of researchers. (XLSX $11 \mathrm{~kb}$ )

Additional file 6: mtDNA haplogroup frequencies of $55 \mathrm{Mogou}$ samples. (PDF $54 \mathrm{~kb}$ )

Additional file 7: Result of AMOVA variance explained by different groupings of populations according to geography and language. (XLSX $17 \mathrm{~kb}$ )

Additional file 8: Population pairwise genetic distance Fst. (XLSX 12 kb)

Additional file 9: Haplogroup frequencies of Mogou, Hengbei,

Taojiazhai, and modern Chinese groups. (XLSX 26 kb)

Additional file 10: Bayesian posterior output of Model 1. (XLSX $12 \mathrm{~kb}$ )

\section{Abbreviations}

3-D: Three dimensions; ABC: Approximate Bayesian Computation; AMG-PCR: PCR analysis of the X-Y Amelogenin Gene; APLP: Amplified product-length polymorphisms; AR: Acceptance-rejection; HVS-I: Hyper variable sequence I; LR: Weightedmultinomial logistic regression; mtDNA: Mitochondrial DNA; NRY: Nonrecombining region of Y-chromosome; PCA: Principal Component Analysis; PCR: Polymerase chain reaction; SNP: Single nucleotide polymorphism

\section{Acknowledgements}

We thank the Institute of Cultural and Historical Relics and Archaeology in Gansu Province, China, for providing the samples and Yongsheng Zhao from Shandong University for anthropological work.

\section{Funding}

This work was supported by the National Natural Science Foundation of China, grant numbers 31,371,266 (Grant Recipient: Hui Zhou), 31,200,935 (Grant Recipient: Chunxiang Li), and 41,672,021 (Grant Recipient: Qiaomei Fu), National Social Science Foundation of China; Grant number: 11\&ZD182 (Grant Recipient: Hong Zhu) and the Key Research Program of Frontier Sciences of CAS (QYZDB-SS W-DQC003; Grant Recipient: Qiaomei Fu).

\section{Availability of data and materials}

The data supporting the results of this article were submitted to GenBank under accession numbers: KX085423-KX085477.

\section{Authors' contributions}

$J \mathrm{~L}, \mathrm{WZ}$, and $\mathrm{YZ}$ conceived and designed the study. JL, AMSK, and QF performed the analysis and wrote the manuscript. CL, Hong Zhu, and Hui Zhou helped in interpreting results and improving the manuscript. All authors read and approved the final manuscript.

Ethics approval and consent to participate

No Ethics committee approval was required to conduct this research project.

\section{Consent for publication}

No living human subjects were part of the study, thus no consent to participate or to publish the data was required.

\section{Competing interests}

The authors declare that they have no competing interests.

\section{Publisher's Note}

Springer Nature remains neutral with regard to jurisdictional claims in published maps and institutional affiliations.

\section{Author details}

${ }^{1}$ College of Life Science, Jilin University, Changchun 130023, People's Republic of China. ${ }^{2}$ Ancient DNA Laboratory, Research Center for Chinese Frontier Archaeology, Jilin University, Changchun 130012, People's Republic of China. ${ }^{3}$ Key Laboratory of Vertebrate Evolution and Human Origins of Chinese Academy of Sciences, IVPP, CAS, Beijing 100044, People's Republic of China.

Received: 25 March 2017 Accepted: 17 November 2017

Published online: 04 December 2017

\section{References}

1. Zhao YB, Yu CC, Zhou H. Study on the origin and development of the Han Chinese. J Jilin Norm Univ ( Natural Science Edition). 2012;4:45-9.

2. Ye W. On the formation of the Han nationality. J Anc Civilizations. 2011;5(3): $1-21$.

3. An C, Ji D, Chen F, Dong G, Wang H, Dong W, Zhao X. Evolution of prehistoric agriculture in central Gansu Province, China: a case study in Qin'an and Li County. Chinese Sci Bull. 2010;55(18):1925-30.

4. Wang M-k. From the Qiang barbarians to the Qiang nationality: the making of a new Chinese boundary. Taipei: Institute of Ethnology, Academia Sinica; 1999. p. 43-80.

5. Liu J, Wang Z. Brief on the origin, deposits and changes of the three great clans Di-Qiang, BaiYue and BaiPu. J Yunnan Agric Univ. 2007;1(2):76-8.

6. Zhao YB, Li HJ, Li SN, Yu CC, Gao SZ, Xu Z, Jin L, Zhu H, Zhou H. Ancient DNA evidence supports the contribution of Di-Qiang people to the han Chinese gene pool. Am J Phys Anthropol. 2011;144(2):258-68.

7. Li M, Yang X, Wang H, Wang $\mathrm{Q}$, Jia X, Ge Q. Starch grains from dental calculus reveal ancient plant foodstuffs at Chenqimogou site, Gansu Province. Sci China Earth Sci. 2010:40(4):486-92.

8. Zhao Y. A Research on the Human Skeletons of Mogou Graveyard, Lintan County, Gansu Province. Changchun: Jilin University; 2013.

9. Qian Y, Zhu Y, Mao R, Xie Y. Excavation of Mogou cemetery of Qijia culture in Gansu Province. Cultural Relics. 2009;10:4-24.

10. Duan L, Gong Q. The origin of Di-qiang ethnic Group in Southwest China. J Guangxi University Nationalities (Philosophy and Social Science Edition). 2007:29(4):44-8.

11. Pruvost M, Schwarz R, Correia VB, Champlot S, Braguier S, Morel N, Fernandez-Jalvo Y, Grange T, Geigl EM. Freshly excavated fossil bones are best for amplification of ancient DNA. PNAS. 2007;104(3):739-44.

12. Der Sarkissian C, Balanovsky O, Brandt G, Khartanovich V, Buzhilova A, Koshel S, Zaporozhchenko V, Gronenborn D, Moiseyev V, Kolpakov E, et al. Ancient DNA reveals prehistoric gene-flow from siberia in the complex human population history of north East Europe. PLoS Genet. 2013;9(2): e1003296.

13. Cooper A, Poinar HN. Ancient DNA. Do it right or not at all. Science. 2000; 289(5482):1139.

14. Umetsu K, Tanaka M, Yuasa I, Saitou N, Takeyasu I, Fuku N, Naito E, Ago K, Nakayashiki N, Miyoshi A, et al. Multiplex amplified product-length polymorphism analysis for rapid detection of human mitochondrial DNA variations. Electrophoresis. 2001;22(16):3533-8. 
15. Shinoda K, Adachi N, Guillen S, Shimada I. Mitochondrial DNA analysis of ancient Peruvian highlanders. Am J Phys Anthropol. 2006;131(1):98-107.

16. Kivisild T, Tolk HV, Parik J, Wang Y, Papiha SS, Bandelt HJ, Villems R. The emerging limbs and twigs of the east Asian mtDNA tree. Mol Biol Evol. 2002;19(10):1737-51.

17. Yao YG, Kong QP, Bandelt HJ, Kivisild T, Zhang YP. Phylogeographic differentiation of mitochondrial DNA in Han Chinese. Am J Hum Genet. 2002;70(3):635-51.

18. Hummel S, Herrmann B. Y-chromosome-specific DNA amplified in ancient human bone. Die Naturwissenschaften. 1991;78(6):266-7.

19. Karafet TM, Mendez FL, Meilerman MB, Underhill PA, Zegura SL, Hammer MF. New binary polymorphisms reshape and increase resolution of the human Y chromosomal haplogroup tree. Genome Res. 2008;18(5):830-8.

20. Medina LS, Muzzio M, Schwab M, Costantino ML, Barreto G, Bailliet G. Human Y-chromosome SNP characterization by multiplex amplified product-length polymorphism analysis. Electrophoresis. 2014;35(17):2524-7.

21. Wang CC, Li H. Inferring human history in East Asia from Y chromosomes. Investig Genet. 2013;4(1):11.

22. Su B, Xiao C, Deka R, Seielstad MT, Kangwanpong D, Xiao J, Lu D, Underhill P, Cavalli-Sforza L, Chakraborty R, et al. Y chromosome haplotypes reveal prehistorical migrations to the Himalayas. Hum Genet. 2000;107(6):582-90.

23. Star B, Nederbragt AJ, Hansen MHS, Skage M, Gilfillan GD, Bradbury IR, Pampoulie C, Stenseth NC, Jakobsen KS, Jentoft S. Palindromic sequence artifacts generated during next generation sequencing library preparation from historic and ancient DNA. PLoS One. 2014;9(3):e89676.

24. Fu Q, Meyer M, Gao X, Stenzel U, Burbano HA, Kelso J, Paabo S. DNA analysis of an early modern human from Tianyuan cave. China PNAS. 2013; 110(6):2223-7.

25. Excoffier L, Smouse PE, Quattro JM. Analysis of molecular variance inferred from metric distances among DNA haplotypes: application to human mitochondrial DNA restriction data. Genetics. 1992;131(2):479-91.

26. Excoffier L, Laval G, Schneider S. Arlequin (version 3.0): an integrated software package for population genetics data analysis. Evol Bioinforma. 2005;1:47-50.

27. Stefan P, Christian NKA. TempNet: a method to display statistical parsimony networks for heterochronous DNA sequence data. Methods Ecol Evol. 2011. 2(6):663-7.

28. Drummond AJ, Suchard MA, Xie D, Rambaut A. Bayesian phylogenetics with BEAUti and the BEAST 1.7. Mol Biol Evol. 2012;29(8):1969-73.

29. Shapiro B, Ho SY, Drummond AJ, Suchard MA, Pybus OG, Rambaut A. A Bayesian phylogenetic method to estimate unknown sequence ages. Mol Biol Evol. 2011;28(2):879-87.

30. Excoffier L, Foll M. Fastsimcoal: a continuous-time coalescent simulator of genomic diversity under arbitrarily complex evolutionary scenarios. Bioinformatics. 2011;27(9):1332-4.

31. Beaumont MA, Zhang W, Balding DJ. Approximate Bayesian computation in population genetics. Genetics. 2002;162(4):2025-35.

32. Alzualde A, Izagirre N, Alonso S, Alonso A, Albarran C, Azkarate A, de la Rua C. Insights into the "isolation" of the Basques: mtDNA lineages from the historical site of Aldaieta (6th-7th centuries AD). Am J Phys Anthropol. 2006; 130(3):394-404.

33. Vernesi C, Caramelli D, Dupanloup I, Bertorelle G, Lari M, Cappellini E, Moggi-Cecchi J, Chiarelli B, Castri L, Casoli A, et al. The Etruscans: a population-genetic study. Am J Hum Genet. 2004;74(4):694-704.

34. Metspalu M, Kivisild T, Metspalu E, Parik J, Hudjashov G, Kaldma K, Serk P, Karmin M, Behar DM, Gilbert MT, et al. Most of the extant mtDNA boundaries in south and southwest Asia were likely shaped during the initial settlement of Eurasia by anatomically modern humans. BMC Genet. 2004;5:26

35. Lippold S, Xu H, Ko A, Li M, Renaud G, Butthof A, Schroder R, Stoneking M. Human paternal and maternal demographic histories: insights from highresolution Y chromosome and mtDNA sequences. Investig Genet. 2014;5:13.

36. Fu Q, Li H, Moorjani P, Jay F, Slepchenko SM, Bondarev AA, Johnson PL, Aximu-Petri A, Prufer K, de Filippo C, et al. Genome sequence of a 45,000-yearold modern human from western Siberia. Nature. 2014;514(7523):445-9.

37. Changchun Y, Li X, Xiaolei Z, Hui Z, Hong Z. Genetic analysis on Tuoba Xianbei remains excavated from Qilang Mountain cemetery in Qahar right wing middle banner of Inner Mongolia. FEBS Lett. 2006;580(26):6242-6.

38. Wang H, Ge B, Mair VH, Cai D, Xie C, Zhang Q, Zhou H, Zhu H. Molecular genetic analysis of remains from Lamadong cemetery, Liaoning, China. Am J Phys Anthropol. 2007;134(3):404-11.
39. Yu CC, Zhao YB, Zhou H. Genetic analyses of Xianbei populations about 1,500-1,800 years old. Russ J Genet. 2014;50(3):308-14.

40. Zhao Y. The Genetic Research of Maternal Origin of Northern Han Chinese. Changchun: Jilin University; 2011.

41. Zhao X. Physical Anthropological and Molecular Archaeological Research on Ancient Populations in Western Liaoning before Qin Dynasty. Changchun: Jilin University; 2009

42. Yao YG, Kong QP, Man XY, Bandelt HJ, Zhang YP. Reconstructing the evolutionary history of China: a caveat about inferences drawn from ancient DNA. Mol Biol Evol. 2003;20(2):214-9.

43. Wen B, Li H, Lu D, Song X, Zhang F, He Y, Li F, Gao Y, Mao X, Zhang L, et al. Genetic evidence supports demic diffusion of Han culture. Nature. 2004; 431(7006):302-5.

44. Kong QP, Yao YG, Liu M, Shen SP, Chen C, Zhu CL, Palanichamy MG, Zhang YP. Mitochondrial DNA sequence polymorphisms of five ethnic populations from northern China. Hum Genet. 2003;113(5):391-405.

45. Qian YP, Chu ZT, Dai Q, Wei CD, Chu JY, Tajima A, Horai S. Mitochondrial DNA polymorphisms in Yunnan nationalities in China. J Hum Genet. 2001; 46(4):211-20.

46. Yao YG, Nie L, Harpending H, Fu YX, Yuan ZG, Zhang YP. Genetic relationship of Chinese ethnic populations revealed by mtDNA sequence diversity. Am J Phys Anthropol. 2002;118(1):63-76

47. Wen B, Xie X, Gao S, Li H, Shi H, Song X, Qian T, Xiao C, Jin J, Su B, et al. Analyses of genetic structure of Tibeto-Burman populations reveals sexbiased admixture in southern Tibeto-Burmans. Am J Hum Genet. 2004;74(5): 856-65.

48. Wen B, Li H, Gao S, Mao X, Gao Y, Li F, Zhang F, He Y, Dong Y, Zhang Y, et al. Genetic structure of Hmong-mien speaking populations in East Asia as revealed by mtDNA lineages. Mol Biol Evol. 2005;22(3):725-34.

49. Li H, Cai X, Winograd-Cort ER, Wen B, Cheng X, Qin Z, Liu W, Liu Y, Pan S, Qian J, et al. Mitochondrial DNA diversity and population differentiation in southern East Asia. Am J Phys Anthropol. 2007;134(4):481-8.

50. Pritchard JK, Seielstad MT, Perez-Lezaun A, Feldman MW. Population growth of human $Y$ chromosomes: a study of $Y$ chromosome microsatellites. Mol Biol Evol. 1999;16(12):1791-8.

51. Neuenschwander S, Largiader CR, Ray N, Currat M, Vonlanthen P, Excoffier L. Colonization history of the Swiss Rhine basin by the bullhead (Cottus Gobio): inference under a Bayesian spatially explicit framework. Mol Ecol. 2008;17(3):757-72.

52. Fu Q, Mittnik A, Johnson PL, Bos K, Lari M, Bollongino R, Sun C, Giemsch L, Schmitz $R$, Burger J, et al. A revised timescale for human evolution based on ancient mitochondrial genomes. Curr Biol. 2013;23(7):553-9.

\section{Submit your next manuscript to BioMed Central and we will help you at every step:}

- We accept pre-submission inquiries

- Our selector tool helps you to find the most relevant journal

- We provide round the clock customer support

- Convenient online submission

- Thorough peer review

- Inclusion in PubMed and all major indexing services

- Maximum visibility for your research

Submit your manuscript at www.biomedcentral.com/submit
) Biomed Central 